\title{
Biochemical events leading to the diversion of carbon into storage lipids in the oleaginous fungi Mucor circinelloides and Mortierella alpina
}

\author{
James P. Wynn, ${ }^{1}$ Adil A. Hamid, ${ }^{2}$ Yonghua $\mathrm{Li}^{1}$ and Colin Ratledge ${ }^{1}$
}

Author for correspondence: James P. Wynn. Tel: +44 1482 465507. Fax: +44 1482465458. e-mail: j.p.wynn@biosci.hull.ac.uk

1 Centre for Advanced Lipid Research, Department of Biological Sciences, University of Hull, Hull HU6 7RX, UK

2 Department of Microbiology, Universitii Kebangsaan, Malaysia, 43600 Bangi, Salangor Darul Ehsan, Malaysia

\begin{abstract}
The biochemical events associated with the onset of lipid accumulation in Mucor circinelloides and Mortierella alpina, under conditions of nitrogenlimited growth, have been elucidated; they differ in key aspects from those described in oleaginous yeasts. The NAD+ : isocitrate dehydrogenases of Mc. circinelloides and Mort. alpina were not absolutely dependent on AMP for activity. Furthermore, changes in the cellular adenine nucleotide pools and energy charge were different from those reported for oleaginous yeasts. In Mc. circinelloides ATP, ADP and AMP concentrations all decreased by $50 \%$ after nitrogen limitation, leading to a constant energy charge at the expense of the size of the total adenylate pool. Pyruvate carboxylase in Mc. circinelloides was cytosolic, having implications for the organization of lipid synthesis in filamentous fungi. As a result of the data obtained, a revised and more concerted mechanism for the initiation of storage lipid accumulation is put forward for filamentous fungi.
\end{abstract}

Keywords: AMP deaminase, $\mathrm{NAD}^{+}$: isocitrate dehydrogenase, lipid accumulation

\section{INTRODUCTION}

As the nutritional benefits of certain long-chain polyunsaturated fatty acids are becoming appreciated so the demand for oils rich in these fatty acids is expanding. In particular, the roles of arachidonic acid [20:4n-6] (ARA) and docosahexaenoic acid [22:6n-3] (DHA) in neonate brain and nervous development have been reported and this has resulted in the inclusion of these fatty acids in baby formulae (Kyle, 1997). As amenable plant and animal sources for these fatty acids do not exist, oils rich in these fatty acids are being produced commercially using oleaginous micro-organisms. Arachidonic acid is being produced using the zygomycete fungus Mortierella alpina and DHA is being produced using the marine algae Crypthecodinium cohnii and Schizochytrium spp. (Ratledge, 1997; Wynn, 1998).

In attempts to optimize these processes and to realize new ones, a sound understanding of the regulation of cell lipid accumulation in the production organism is

Abbreviations: $\mathrm{dO}_{2}$, dissolved oxygen concentration; NAD:ICDH, $\mathrm{NAD}^{+}$: isocitrate dehydrogenase; PFK, phosphofructokinase. required. Although the biochemical basis of microbial oleaginicity has been elucidated this work has been carried out almost exclusively in yeasts (Botham \& Ratledge, 1979; Boulton \& Ratledge, 1983; Evans \& Ratledge, 1983, 1985a, b). A similar system has been tacitly assumed to apply to other groups of eukaryotic micro-organisms.

All the enzymes thought to be crucial for the accumulation of substantial amounts of storage lipid are present in both oleaginous yeasts and filamentous fungi. However, it has become apparent in the course of our more recent work that the regulation of lipogenesis may differ between filamentous fungi and yeasts. In the present study Mucor circinelloides was used as the principal model for oleaginous filamentous fungi. However, because of its commercial importance Mort. alpina was also included in order to verify the key results. This report indicates a number of significant differences in the biochemistry of lipid accumulation between oleaginous yeasts and oleaginous filamentous fungi. A revised and more concerted mechanism for the initiation of storage lipid synthesis when filamentous fungi experience $\mathrm{N}$ limiting conditions is put forward. These findings have implications not only for the production of single-cell 
oils but also for other commercial fermentations using filamentous fungi (e.g. those producing citric acid and gibberellic acid) in which lipid synthesis represents an undesirable by-product and therefore an unnecessary waste of substrate.

\section{METHODS}

Chemicals. Unless otherwise stated all fine chemicals were purchased from Sigma.

Cultivation of fungi. Mucor circinelloides CBS 108.16 and Mortierella alpina Peyron CBS 696.70 were initially cultivated in 1 litre magnetically stirred bottles containing $800 \mathrm{ml}$ Kendrick medium (N-limiting) (Kendrick \& Ratledge, 1992). These cultures were incubated for $16 \mathrm{~h}$ at $30{ }^{\circ} \mathrm{C}$ then used at $10 \%(\mathrm{v} / \mathrm{v})$ to inoculate 4 litre (working volume) fermenters containing modified Kendrick medium containing ammonium tartrate at $2 \mathrm{~g} \mathrm{l}^{-1}$ for both fungi, with glucose at $50 \mathrm{~g} \mathrm{l}^{-1}$ for Mc. circinelloides and $30 \mathrm{~g} \mathrm{l}^{-1}$ for Mort. alpina. Fermenters were incubated at $30^{\circ} \mathrm{C}$, stirred at 500 r.p.m. with aeration at 0.5 vol. vol. ${ }^{-1} \mathrm{~min}^{-1}$ and $\mathrm{pH}$ maintained at 5.5 by automatic addition of $\mathrm{KOH}$ and $\mathrm{HCl}$.

Production of cell extracts. Biomass was harvested by filtration (under reduced pressure) through a Whatman no. 1 filter and washed with cold distilled water. Cell extracts for the determination of enzyme activities were prepared by suspending mycelia in an extraction buffer (Wynn et al., 1998) and disrupted either by passage twice through a French pressure cell at $35 \mathrm{MPa}$ or by a single pass through a 'One Shot' cell disrupter (Constant Systems) at $640 \mathrm{MPa}$. Disrupted cell suspensions were centrifuged at $10000 \mathrm{~g}$ for $10 \mathrm{~min}$ and the supernatant retained for enzyme analysis. Protein concentrations were determined using the method of Bradford (1976) with BSA as a standard.

Preparation of spheroplasts and isolation of mitochondria. Mc. circinelloides was grown in 1 litre stirred bottles, as described above. Harvested biomass was washed twice with spheroplasting buffer $(50 \mathrm{mM}$ Tris $/ \mathrm{HCl}, \mathrm{pH} 6.5$, containing $1.2 \mathrm{M}$ sorbitol) then suspended in the same buffer containing chitinase/chitosanase preparation (Vanheeswijck, 1984) at $2 \mathrm{mg} \mathrm{ml}^{-1}$ and incubated for $3 \mathrm{~h}$ at $30^{\circ} \mathrm{C}$. The treated biomass was collected by centrifugation $\left(10000 \mathrm{~g}\right.$ for $10 \mathrm{~min}$ at $\left.4{ }^{\circ} \mathrm{C}\right)$ and the spheroplasts formed were disrupted by resuspension in $50 \mathrm{mM}$ Tris $/ \mathrm{HCl}(\mathrm{pH} 7.5)$ and incubated at $20^{\circ} \mathrm{C}$ for $1 \mathrm{~h}$. The disrupted cells were fractionated by centrifugation at $5000 \mathrm{~g}$ for $10 \mathrm{~min}$ and then the supernatant centrifuged at $16000 \mathrm{~g}$ for $20 \mathrm{~min}$. The cell preparations were maintained at $4{ }^{\circ} \mathrm{C}$ throughout. The supernatant and the pellet formed at $16000 \mathrm{~g}$ were retained as the 'cytosolic' and 'mitochondrial' fractions respectively.

Estimation of enzyme activities. $\mathrm{NAD}^{+}$: isocitrate dehydrogenase (NAD:ICDH) was assayed using the method of Kornberg (1955). AMP deaminase activity was assayed using a reaction volume containing $100 \mathrm{mM} \mathrm{KH_{2 }} \mathrm{PO}_{4} / \mathrm{KOH}(\mathrm{pH}$

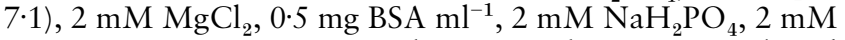
ATP $(\mathrm{pH} 7 \cdot 1), 5 \mathrm{mM}$ AMP. The assay volume was incubated for 10 to 30 min at $30^{\circ} \mathrm{C}$ and the $\mathrm{NH}_{4}^{+}$liberated was quantified using the indophenol method (Chaney \& Marbach, 1962). Adenylate kinase was determined using a method based on that of Sottocasa et al. (1967). The reaction volume contained $67 \mathrm{mM}$ Tris/ $\mathrm{HCl}$ ( $\mathrm{pH} 7.5$ ), $5 \mathrm{mM}$ ADP, 0.5 units hexokinase/ glucose-6-phosphate dehydrogenase mix (from baker's yeast), $5 \mathrm{mM} \mathrm{MgSO}_{4}, 0 \cdot 2 \mathrm{mM} \mathrm{NADP}{ }^{+}$and $10 \mathrm{mM}$ glucose. The increase in $A_{340}$ was measured. Phosphofructokinase (PFK) was assayed as described by Sols \& Salas (1966), citrate synthase as described by Parvin (1969), succinate dehydrogenase as described by Schwitzguebel et al. (1981), pyruvate kinase as described by Worthington Enzymes (1979) and pyruvate carboxylase as described by Seubert \& Weicker (1969). The assay reactions for citrate synthase, succinate dehydrogenase, pyruvate kinase and pyruvate carboxylase were supplemented with $0 \cdot 1 \%(\mathrm{w} / \mathrm{v})$ Triton X-100.

Determination of nucleotide concentrations. The concentrations of adenine nucleotides (ATP, ADP and AMP) were determined using the luciferin/luciferase system to quantify ATP (Speilmann et al., 1982). Samples $(20 \mathrm{ml})$ from the fermenter were rapidly quenched $(<0.5 \mathrm{~s})$ by collection in sterile Universal tubes containing $4 \mathrm{ml}$ conc. $\mathrm{H}_{2} \mathrm{SO}_{4}$. Quenched samples were diluted 1:10 with $5 \mathrm{mM}$ glycylglycine/KOH buffer ( $\mathrm{pH} 7 \cdot 8$ ) and, if necessary, the $\mathrm{pH}$ adjusted to $7 \cdot 8$. Cell debris was removed by centrifugation at $10000 \mathrm{~g}$ for $10 \mathrm{~min}$ and then the supernatant was diluted 1:10 with glycylglycine buffer. The diluted supernatant was either analysed immediately or stored at $-20^{\circ} \mathrm{C}$ for a maximum of 2 weeks prior to analysis. ATP was quantified by adding $50 \mu \mathrm{l}$ of the sample prepared above to $50 \mu \mathrm{l} 100 \mathrm{mM}$ glycylglycine buffer ( $\mathrm{pH} 7.8$ ) containing $5 \mathrm{mM} \mathrm{MgSO}_{4}, 0.5 \mathrm{mM}$ phosphoenolpyruvate and $100 \mu \mathrm{l}$ ATP assay mix (Sigma). ADP was quantified by conversion to ATP in the same reaction mixture as described above but with the addition of 1 unit pyruvate kinase (type 1: crude preparation from rabbit muscle) and incubated at $37^{\circ} \mathrm{C}$ for $10 \mathrm{~min}$ prior to the addition of the ATP assay mix. ADP was calculated by subtraction of the amount of ATP detected previously. AMP was likewise quantified by its conversion to ATP and then subtraction of the amount of ATP + ADP detected in the sample. AMP was converted to ATP by addition of 1 unit myokinase (from porcine muscle) and 1 unit pyruvate kinase followed by a $10 \mathrm{~min}$ incubation at $37^{\circ} \mathrm{C}$ prior to the addition of the ATP assay mix.

Determination of culture dry weight. A $20 \mathrm{ml}$ sample of the culture was harvested on to a washed, dried and pre-weighed filter (Whatman no. 1). The filtrate was retained and analysed for culture glucose and ammonium concentrations (see below). Harvested biomass was washed with distilled water and then dried at $110^{\circ} \mathrm{C}$ to constant weight. The weight of the biomass was determined gravimetrically.

Analysis of the culture supernatant. The glucose concentration in the culture medium was determined using a GODPerid test kit (Boehringer Mannheim) according to the manufacturer's instructions. The ammonium concentration in the culture filtrate was determined using the indophenol test (Chaney \& Marbach, 1962).

Analysis of intracellular metabolites. Samples were collected into tubes containing $4 \mathrm{ml} 5.8 \mathrm{M} \mathrm{HClO}_{4}$. Samples were centrifuged at $10000 \mathrm{~g}$ for $10 \mathrm{~min}$ and the supernatant adjusted to $\mathrm{pH} 7 \cdot 4$ with $\mathrm{NaOH}$. The isocitrate and citrate concentrations in the samples were determined as described by Siebert (1974) and Dagley (1974) respectively. Samples of culture medium were also analysed for isocitrate and citrate to allow corrections to be made for extracellular metabolites.

Determination of culture $\mathbf{d O}_{2}$ and $\mathbf{C O}_{2}$ evolution. The dissolved oxygen concentration $\left(\mathrm{dO}_{2}\right)$ of the culture medium in the fermenters was continuously recorded using galvanic $\mathrm{O}_{2}$ electrodes (Mettler-Toledo, Woburn, MA, USA) as a percentage of the $\mathrm{O}_{2}$ concentration in the equilibrated culture medium immediately prior to inoculation. The $\mathrm{CO}_{2}$ evolution by the fungal cultures was determined by measuring the $\mathrm{CO}_{2}$ in the fermenter exhaust using a $\mathrm{CO}_{2}$ analyser (Analytical Development Co., Hoddesdon, UK). 


\section{RESULTS}

The $\mathrm{dO}_{2}$ in $M$ c. circinelloides cultures decreased during the period of active cell growth in the presence of $\mathrm{NH}_{4}^{+}$ in the culture medium (Fig. 1). After N-exhaustion the $\mathrm{dO}_{2}$ recovered to an equilibrium point between $70 \%$ and $80 \%$. The $\mathrm{CO}_{2}$ content of the fermenter exhaust gas exhibited similar but opposite trends to the $\mathrm{dO}_{2}$ data, with $\mathrm{CO}_{2}$ concentration in the exhaust gas increasing during active growth (i.e. prior to $\mathrm{N}$-exhaustion) then decreasing as the culture experienced N-limitation. Changes in $\mathrm{CO}_{2}$ evolution were rapid, occurring within minutes of the exhaustion of the $\mathrm{N}$-source.

The NAD : ICDH activities of two oleaginous fungi, $M c$. circinelloides and Mort. alpina, were examined at a range of isocitrate and AMP concentrations in vitro (see Fig. 2a, b). The fungal enzymes were not dependent on AMP for activity in the presence of saturating levels of isocitrate. At low isocitrate concentrations AMP increased the affinity of the NAD:ICDH for isocitrate. The $K_{\mathrm{m}}$ of NAD:ICDH for isocitrate in the presence of $1 \mathrm{mM}$ AMP was tenfold lower in Mc. circinelloides (from $3.2 \mathrm{mM}$ to $0.3 \mathrm{mM}$ ) and twofold lower in Mort. alpina (from $4.6 \mathrm{mM}$ to $2.7 \mathrm{mM}$ ) than when determined in the absence of AMP. As a result of the increased affinities for isocitrate of the NAD:ICDHs from the fungi in the presence of AMP, activity was detectable and maximal at lower concentrations of isocitrate when AMP was present in the system (see Fig. 2a, b).

Attempts to determine the intracellular concentration of isocitrate in $M c$. circinelloides failed to detect this metabolite at any stage of growth, the limit of detection being $<1.5 \mathrm{nmol}$ (mg dry $\mathrm{wt})^{-1}$. This corresponded to an intracellular concentration of less than $1 \mathrm{mM}$ (see

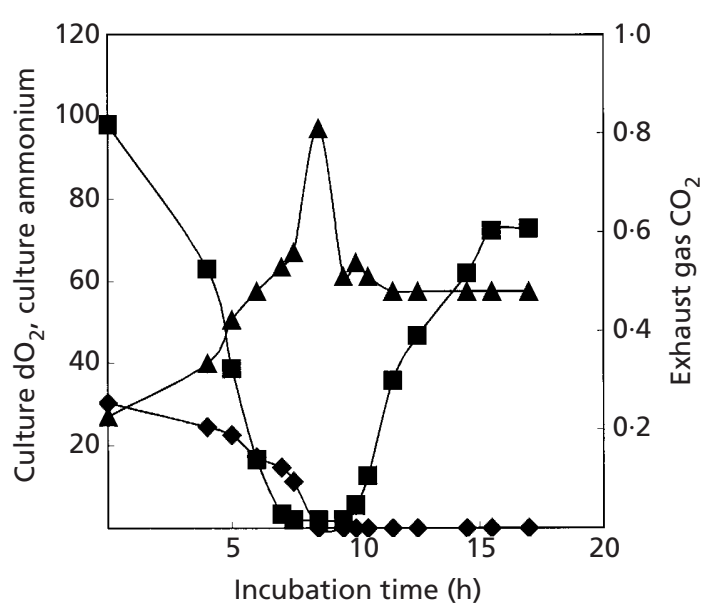

Fig. 1. Effect of $\mathrm{N}$-exhaustion on $\mathrm{O}_{2}$ consumption and $\mathrm{CO}_{2}$ evolution by $M c$. circinelloides. The $\mathrm{dO}_{2}$ in the culture medium and $\mathrm{CO}_{2}$ in the exhaust gas were determined during growth of Mc. circinelloides in a 4 litre fermenter under batch conditions on a medium with a high $\mathrm{C}: \mathrm{N}$ ratio. This experiment was repeated three times and representative data are presented. Culture ammonium tartrate concentration $\left(\mathrm{g} \mathrm{I}^{-1}\right) ; \mathbf{\square}, \mathrm{dO}_{2}(\%$ original saturation); $\boldsymbol{\Delta}$, exhaust gas $\mathrm{CO}_{2}(\%, \mathrm{v} / \mathrm{v})$.
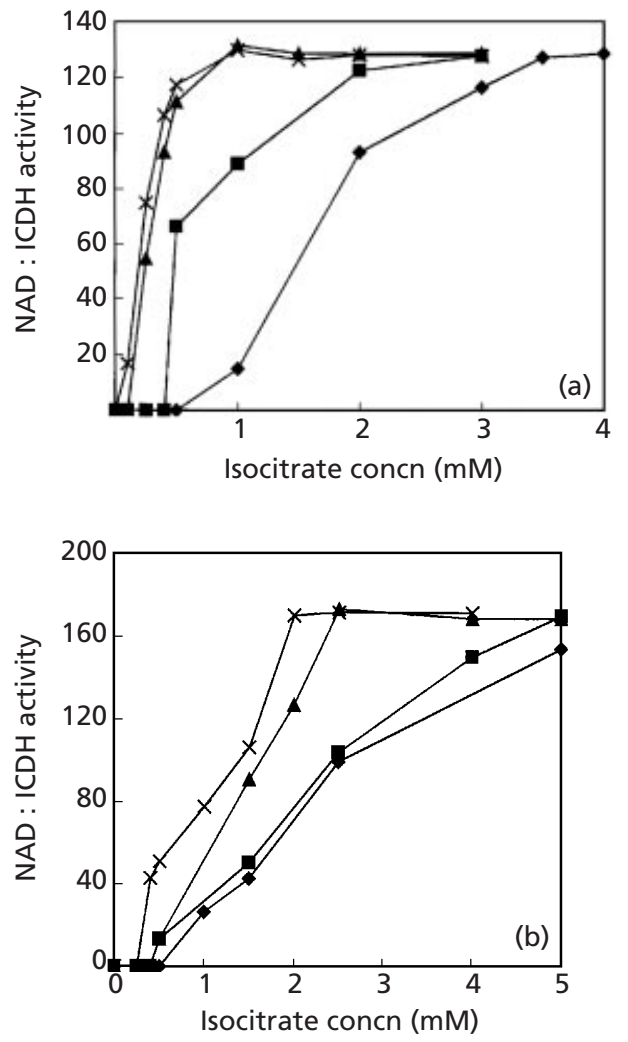

Fig. 2. Effect of isocitrate and AMP concentration on the activity of $\mathrm{NAD}^{+}: \mathrm{ICDH}$ from (a) Mc. circinelloides and (b) Mort. alpina. The activity of $\mathrm{NAD}^{+}: \mathrm{ICDH}\left[\mathrm{nmol} \mathrm{min}^{-1}\left(\mathrm{mg}\right.\right.$ protein) $\left.{ }^{-1}\right]$ in a dialysed cell extract was measured, in vitro, in the presence and absence of AMP. This experiment was repeated three times and representative data are presented. AMP concentrations: $\bullet$, $0 \mathrm{mM} ; \boldsymbol{\square}, 0.1 \mathrm{mM} ; \boldsymbol{\Delta}, 0.5 \mathrm{mM} ; \times, 1.0 \mathrm{mM}$.

Discussion). In contrast, intracellular citrate was detectable both before and after $\mathrm{N}$-exhaustion. A fourfold increase in the citrate concentration, from $3.7 \pm 6 \mathrm{nmol}$ $(\mathrm{mg} \text { dry wt })^{-1}($ mean $\pm \operatorname{SEM} ; n=3)$ to $16 \cdot 1 \pm \overline{4} \cdot 7 \mathrm{nmol}$ $(\mathrm{mg} \text { dry } \mathrm{wt})^{-1}(n=5)$, occurred after N-exhaustion, corresponding to an intracellular citrate concentration of $1-2 \mathrm{mM}$ prior to $\mathrm{N}$-exhaustion and $4-8 \mathrm{mM}$ after $\mathrm{N}$ exhaustion.

When the activity of AMP deaminase was determined, in triplicate batch cultures of $M c$. circinelloides, an increase in activity was reproducibly observed at the point when the cultures became N-limited and was coincident with the onset of lipid accumulation (see Fig. $3 a)$. The increase in activity of AMP deaminase was, however, transitory and activity returned to basal levels within $5 \mathrm{~h}$ of N-exhaustion (see Fig. 3a). Similar data were obtained with Mort. alpina (Fig. 3b).

Throughout the cultivation period, the activity of adenylate kinase was high in comparison to the activity of AMP deaminase and it increased over threefold after the depletion of the culture $\mathrm{N}$-source. The specific activity of adenylate kinase in $M c$. circinelloides was $518 \pm 154 \mathrm{nmol} \mathrm{min}^{-1}(\mathrm{mg} \text { protein })^{-1}(n=5)$ prior to $\mathrm{N}$ - 

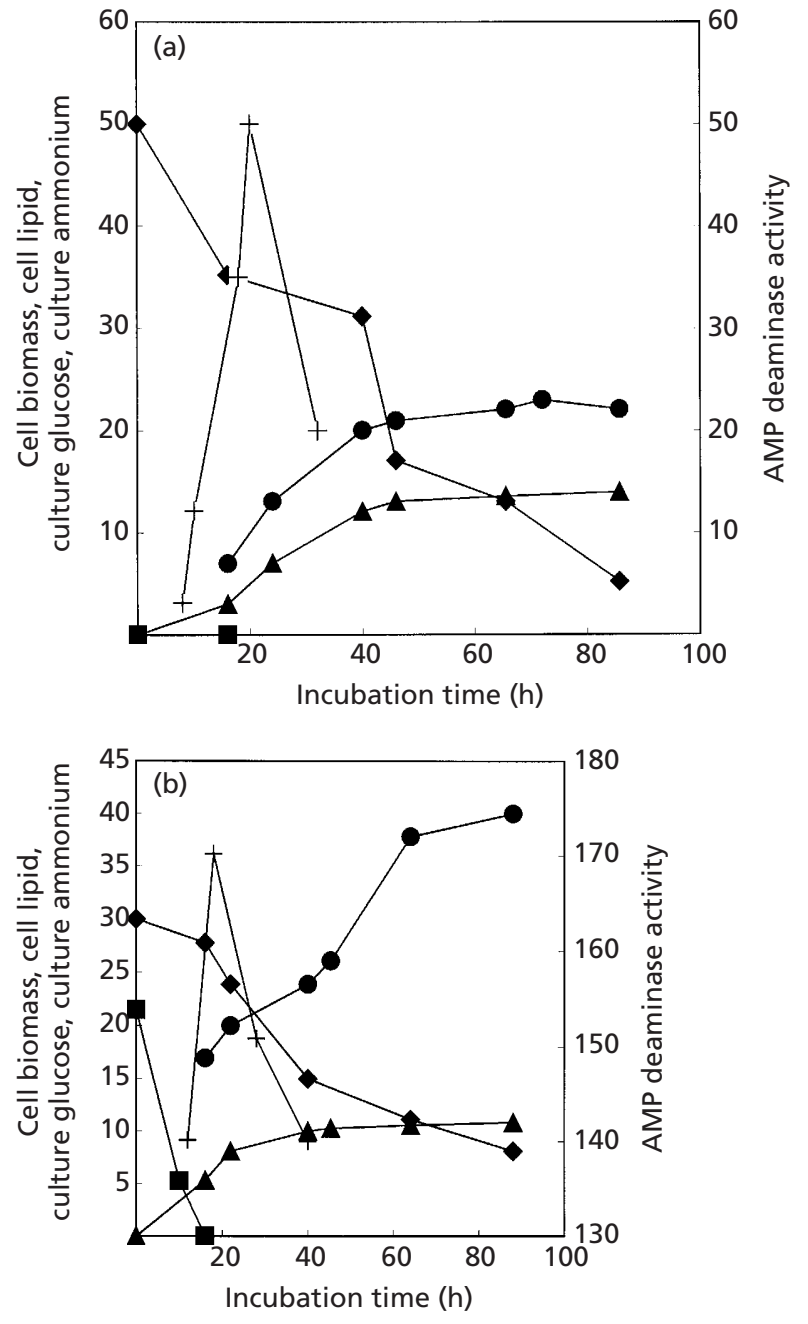

Fig. 3. Changes in cell growth and AMP deaminase activity in response to depletion of the $\mathrm{N}$-source in (a) Mc. circinelloides and (b) Mort. alpina in a 4 litre fermenter. The AMP deaminase activity [nmol $\mathrm{min}^{-1}$ (mg protein $)^{-1}$ ] was determined at intervals during growth in a 4 litre fermenter under batch conditions on a medium with a high $\mathrm{C}: \mathrm{N}$ ratio. This experiment was repeated three times and representative data are presented. $\boldsymbol{\Delta}$, Cell biomass $\left(\mathrm{g} \mathrm{I}^{-1}\right) ; 0$, cell lipid $(\%, \mathrm{w} / \mathrm{v}$, dry wt); $\diamond$, culture glucose concentration $\left(\mathrm{g} \mathrm{I}^{-1}\right) ;+$, AMP deaminase activity [nmol min ${ }^{-1}$ (mg protein $\left.)^{-1}\right] ; \boldsymbol{\square}$, culture ammonium concentration $\left(\mathrm{g} \mathrm{I}^{-1}\right)$.

exhaustion and $1739 \pm 226 \mathrm{nmol} \mathrm{min}^{-1}(\mathrm{mg} \text { protein })^{-1}$ $(n=4)$ after N-exhaustion.

The stimulation of AMP deaminase and adenylate kinase activities, at the time of $\mathrm{N}$-exhaustion, led to an almost immediate decrease in the concentrations of ATP, ADP and AMP. The concentrations of all three adenine nucleotides decreased by $50 \%$ during the $2-3 \mathrm{~h}$ period immediately after $\mathrm{N}$-exhaustion (see Fig. 4). ADP was the most abundant nucleotide [concentration varying from 3.7 to $1.1 \mathrm{nmol}(\mathrm{mg} \mathrm{dry} \mathrm{wt})^{-1}$ ], followed by ATP [between 1.6 and $0.5 \mathrm{nmol}(\mathrm{mg} \text { cell dry wt })^{-1}$ ]. The AMP concentration was consistently the lowest $[0 \cdot 9-$ $\left.0.4 \mathrm{nmol}(\mathrm{mg} \text { dry } \mathrm{wt})^{-1}\right]$. Although the cellular total

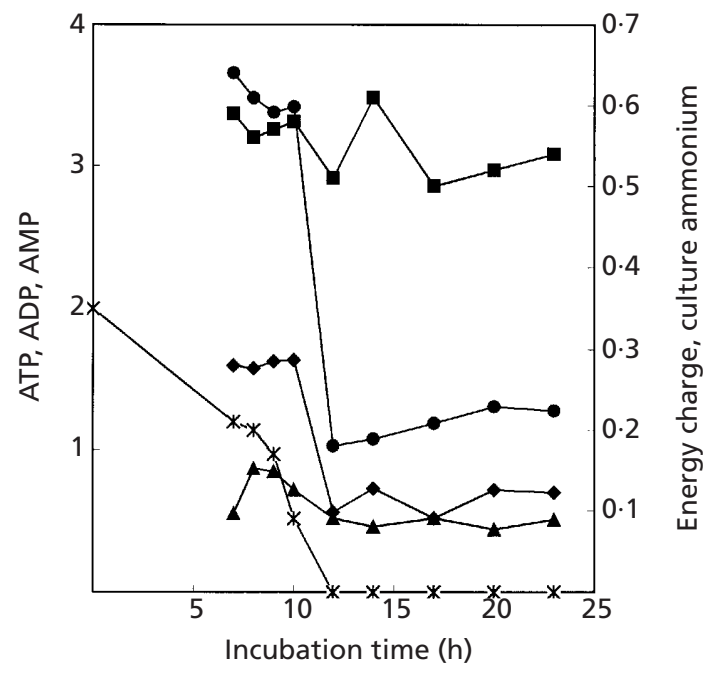

Fig. 4. Changes in the intracellular adenine nucleotide concentrations and energy charge in Mc. circinelloides in response to $\mathrm{N}$-limitation in a 4 litre fermenter. The intracellular concentrations of ATP, ADP and AMP were determined during the growth of Mc. circinelloides in a 4 litre fermenter under batch conditions on a medium with a high $\mathrm{C}: \mathrm{N}$ ratio. This experiment was repeated three times and representative data are presented. AMP concentration; ADP concentration; $\checkmark$, ATP concentration; $\boldsymbol{\square}$, energy charge; $\times$, culture ammonium tartrate $\left(\mathrm{g} \mathrm{I}^{-1}\right)$. The cellular energy charge (EC) was calculated using the formula $E C=([A T P]+0 \cdot 5[A D P]) /([A M P]+$ $[A D P]+[A T P])$. All adenylate nucleotide concentrations are expressed as $\mathrm{nmol}(\mathrm{mg} \text { dry } \mathrm{wt})^{-1}$.

nucleotide concentration decreased by $50 \%$ at the point when the cells became growth-limited by the depletion of the $\mathrm{N}$-source, the cellular energy charge remained relatively constant at between 0.5 and 0.6 as there were concomitant changes in all three adenine nucleotides.

Both citrate and $\mathrm{NH}_{4}^{+}$affected PFK activity in $M c$. circinelloides, though in an antagonistic fashion (Fig. 5). PFK activity, in vitro, was increased $50 \%$ by $5 \mathrm{mM}$ $\mathrm{NH}_{4}^{+}$. However, higher concentrations of $\mathrm{NH}_{4}^{+}$reversed the stimulation so that at $15 \mathrm{mM} \mathrm{NH}_{4}^{+}$the activity of PFK was equivalent to the activity in the absence of $\mathrm{NH}_{4}^{+}$. Citrate, in contrast, inhibited the activity of PFK in vitro, causing a $50 \%$ decrease in activity at $5 \mathrm{mM}$ and an abolition of activity at $15 \mathrm{mM}$. The effect of $\mathrm{NH}_{4}^{+}$, in the presence of citrate, on the activity of PFK confirmed the antagonistic affect of these two compounds. In the presence of $1 \mathrm{mM}$ citrate, the stimulation of PFK by $4 \mathrm{mM} \mathrm{NH}_{4}^{+}$was maximal and only half that observed in the absence of citrate.

When a cell-free extract from Mc. circinelloides was subjected to subcellular fractionation, the activity of

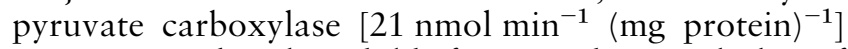
was recovered in the soluble fraction along with that of pyruvate kinase $\left[5 \mathrm{mg} \mathrm{min}^{-1}(\mathrm{mg} \text { protein })^{-1}\right]$ and did not appear in the cytosolic fraction. Pyruvate carboxylase activity was clearly separated from the activity of the mitochondrial marker enzymes citrate synthase $\left.\left[37 \mathrm{nmol} \mathrm{min}^{-1} \text { (mg protein) }\right)^{-1}\right]$ and succinate dehydro- 

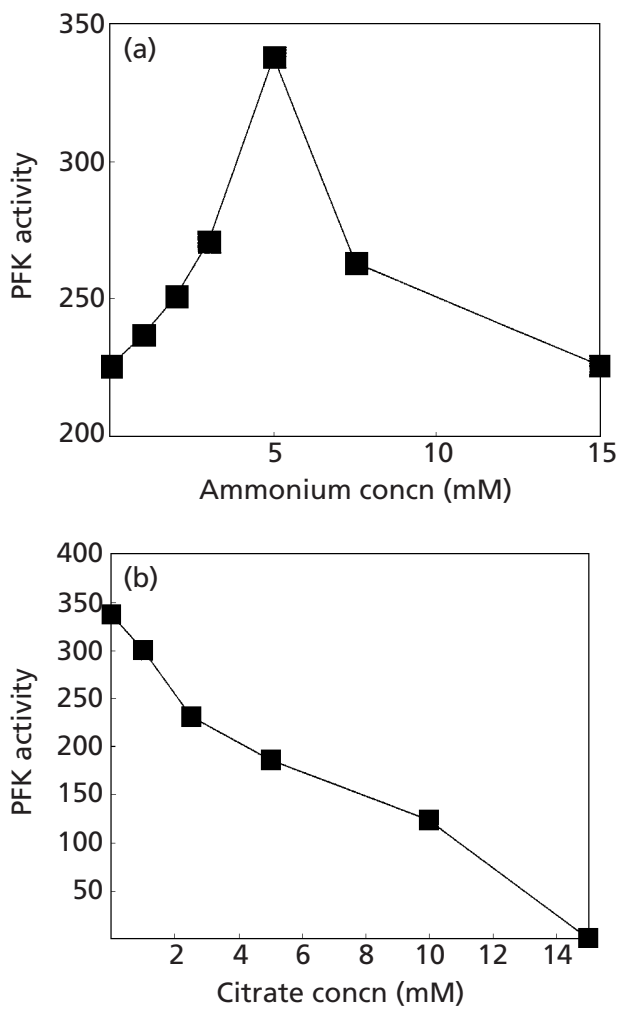

Fig. 5. Effect of (a) $\mathrm{NH}_{4}^{+}$and (b) citrate on the activity of PFK of Mc. circinelloides in vitro. Citrate and $\mathrm{NH}_{4}^{+}$were included in the in vitro assay of PFK to establish the impact of these effectors on the activity [nmol $\mathrm{min}^{-1}(\mathrm{mg} \text { protein })^{-1}$ ] of this enzyme. This experiment was repeated three times and representative data are presented.

genase $\left.\left[32 \mathrm{nmol} \mathrm{min}{ }^{-1} \text { (mg protein }\right)^{-1}\right]$, which were recovered exclusively in the mitochondrial pellet.

\section{DISCUSSION}

\section{Changes in $\mathrm{O}_{2}$ consumption and $\mathrm{CO}_{2}$ evolution in response to $\mathrm{N}$-limiting conditions and implications for metabolic switching}

The decrease in $\mathrm{O}_{2}$ consumption and $\mathrm{CO}_{2}$ evolution at the time of $\mathrm{N}$-exhaustion from the cultures is direct evidence of the down-regulation of cell metabolism in general and the citric acid cycle in particular. As the $\mathrm{dO}_{2}$ of the culture did not return to $100 \%$ saturation the cells evidently remained metabolically active after $\mathrm{N}$-exhaustion, with glucose assimilation continuing and an increase in both cell dry weight and storage lipid content of the cells.

To correlate this switch in metabolic flux to the overall down-regulation of metabolic activity is a large and complex task. However, with our focus being on the mechanism of lipid accumulation we have aimed to elucidate the biochemical events underlying this rapid cellular response to N-limitation and hence the transition from the trophophase to the idiophase when lipid and other secondary products are accumulated. Only by a sound understanding of this biochemistry can rational attempts at increasing lipid/secondary product accumulation using molecular techniques be made. Previous attempts to increase the production of secondary products by gene cloning without a sound biochemical background have highlighted the 'hit and miss' (mainly miss) nature of this approach (Rangasamy \& Ratledge, 2000; Ratledge, 2000; Roehr et al., 1996; Ruijter et al., 2000).

The enzymes thought to be important in the initiation of lipid accumulation (ATP : citrate lyase, AMP deaminase and $\mathrm{NAD}^{+}$: isocitrate lyase) in yeasts (Evans \& Ratledge, $1985 \mathrm{a}, \mathrm{b})$ have all been reported in filamentous fungi (Botham \& Ratledge, 1979; Wynn et al., 1998) and their presence in Mc. circinelloides has been confirmed in this and previous studies (Wynn et al., 1997).

\section{$\mathrm{NAD}^{+}:$ICDH in oleaginous fungi}

The characteristics of the NAD: ICDHs of the two fungi examined were similar (though the enzyme from Mucor had a higher affinity for isocitrate than that from Mortierella) but were clearly distinct from those described for the NAD:ICDH from oleaginous yeasts (Botham \& Ratledge, 1979; Evans et al., 1983; Evans \& Ratledge, 1985b). Both fungi are oleaginous - with $M c$. circinelloides capable of accumulating $25 \%(\mathrm{w} / \mathrm{w}$ dry wt) lipid and Mort. alpina capable of accumulating $40 \%$ lipid (Wynn et al., 1999) - however, the NAD:ICDH activities in these fungi were not absolutely dependent on AMP and, therefore, more closely resembled the enzyme from non-oleaginous micro-organisms (Evans et al., 1983; Atkinson et al., 1965). It is important to note, however, that NAD:ICDH was only active in the absence of AMP at non-physiological concentrations of isocitrate; i.e. $3 \mathrm{mM}$ and $5 \mathrm{mM}$ for $M c$ c circinelloides and Mort. alpina respectively. Although we could not detect isocitrate within the cells it is likely that the concentration of isocitrate will be approximately $5 \%$ of the citrate concentration (Siebert, 1974), which was measured maximally at $15-20 \mathrm{nmol}(\mathrm{mg} \text { dry wt })^{-1}$. This would give a concentration of isocitrate of less than $1 \mathrm{nmol}(\mathrm{mg} \text { dry } \mathrm{wt})^{-1}$, i.e. less than $0.5 \mathrm{mM}$ assuming 2-4 $\mu \mathrm{l} \mathrm{H}_{2} \mathrm{O}$ (mg dry wt) ${ }^{-1}$ (Knowles, 1977). At this concentration of isocitrate, NAD:ICDH would be down-regulated by the decrease in AMP concentration observed in the cells as a result of the increase in AMP deaminase activity triggered by N-exhaustion from the culture medium: see below.

\section{AMP deaminase activity}

Activation of AMP deaminase plays a key role in decreasing the concentration of AMP in oleaginous yeasts entering N-limited growth (Evans \& Ratledge, 1985a). A similar situation occurred in the filamentous fungi studied, with a peak of AMP deaminase activity coincident with $\mathrm{N}$-exhaustion causing a decrease in the intracellular AMP concentration (see below). The de- 
crease in AMP concentration was coincident with the decrease in $\mathrm{CO}_{2}$ evolution (see Fig. 1), which was indicative of a major decrease in the activity of the citric acid cycle. That the increase in activity of AMP deaminase was directly responsible for the decline in activity of NAD:ICDH, thereby affecting the overall activity of the citric acid cycle, is entirely consistent with these observations. The situation is more complex than in oleaginous yeasts in that AMP deaminase subsequently returned to its original activity, but this did not lead to any concomitant increase in AMP concentration or in the rate of $\mathrm{CO}_{2}$ evolution. Therefore, the effect of the increase in AMP deaminase, though transitory, nevertheless may have initiated a cascade of connected biochemical events that rapidly led to the initiation of lipid accumulation.

\section{Changes in adenylate pool size and cellular energy charge}

The increased activity of AMP deaminase led to a rapid decrease in the cellular AMP, from $0.8 \mathrm{nmol}$ (mg dry wt $)^{-1}(0 \cdot 2-0 \cdot 4 \mathrm{mM})$ prior to $N$-exhaustion to $0.5 \mathrm{nmol}$ $(\mathrm{mg} \text { dry wt })^{-1}(0 \cdot 13-0 \cdot 25 \mathrm{mM})$ after $\mathrm{N}$-exhaustion. AMP remained at this concentration even after AMP deaminase returned to its initial activity (Fig. 4). This approximately $50 \%$ decrease in AMP concentration, although not as dramatic as the $90 \%$ decrease reported for some yeasts (Boulton \& Ratledge, 1983; Mitsushima et al., 1978), would nevertheless still lead to a significant down-regulation of NAD:ICDH activity, and thereby rapidly diminish the carbon flux through the citric acid cycle. Although the AMP concentration measured represented the total intracellular, rather than intramitochondrial, concentration this is thought unimportant as the mitochondrial membrane in eukaryotic microorganisms is permeable to AMP (Matsushima et al., 1978; Bartels \& Jensen, 1979). Therefore, the intracellular and intra-mitochondrial concentrations of AMP are likely to be equivalent.

Although a decrease in the AMP concentration associated with the depletion of the $\mathrm{N}$-source in Mc. circinelloides resembles the situation reported for oleaginous yeasts (Boulton \& Ratledge, 1983; Mitsushima et al., 1978), changes in the adenylate pool and the cellular energy charge differed from those previously reported. Whereas in yeasts the decrease in AMP was accompanied by an increase in the intracellular ATP/AMP ratio (Solodovnikova et al., 1998) and, therefore, energy charge, in Mc. circinelloides this did not happen. During the transition from N-replete to $\mathrm{N}$-limited growth, the cellular concentrations of all three adenine nucleotides decreased by approximately $50 \%$ and the energy charge remained constant. This is similar to the situation reported in bacteria and fish, where during metabolic stress the cellular energy charge was maintained within closely defined limits at the expense of the total adenylate pool size, by the combined action of AMP deaminase and adenylate kinase (Atkinson, 1977; Woo \& Chiu, 1997).

\section{Regulatory properties of PFK}

A preliminary study of the PFK of Mc. circinelloides demonstrated regulatory properties similar to those reported for the enzyme from other fungi (Roehr et al., 1996). Activity was stimulated by the presence of $\mathrm{NH}_{4}^{+}$ and inhibited by citrate, with these effectors acting antagonistically. Therefore under N-limiting conditions a decrease in the intracellular $\mathrm{NH}_{4}^{+}$and an increase in citrate concentration would down-regulate the carbon flux through the glycolytic pathway, via inhibition of PFK activity. It is possible that the build-up of citrate due to the down-regulation of the citric acid cycle (see above) plays a role in regulating the rate of glycolysis (due to the inhibition of PFK) and therefore its own synthesis.

\section{Subcellular localization of pyruvate carboxylase}

A cytosolic pyruvate carboxylase activity in $M c$. circinelloides is in accord with the observations in other fungi (Osmani \& Scrutton, 1985; Klitsch et al., 1991). In this regard filamentous fungi are distinct from yeasts, in which both mitochondrial and cytosolic pyruvate carboxylases have been reported (Evans et al., 1983; Rohde et al., 1991; Van Urk et al., 1989), and animals, where pyruvate carboxylase is mitochondrial (Böttger et al., 1969; Taylor et al., 1978). A cytosolic pyruvate carboxylase would allow the cytosolic generation of NADPH for lipid biosynthesis via the co-operation of pyruvate carboxylase, malate dehydrogenase and malic enzyme to produce a 'transhydrogenase cycle' generating NADPH at the expense of NADH and ATP.

\section{Conclusions}

The biochemical mechanism responsible for the initiation of lipid accumulation in oleaginous fungi differs in several fundamental ways from that observed in oleaginous yeasts. As a result, the hypothesis explaining the onset of lipid accumulation in oleaginous yeasts requires modification before it can be applied to filamentous fungi. Although many of the enzymes involved in both systems are the same, the mechanism that operates in filamentous fungi is a somewhat more complicated and concerted process than that reported for yeasts.

The following hypothesis is put forward to explain the switching from active growth to the stationary phase in filamentous fungi.

1. As the $\mathrm{N}$-source in the medium reaches a concentration below the $K_{\mathrm{m}}$ value of the uptake mechanisms the intracellular $\mathrm{NH}_{4}^{+}$concentration decreases. Because $\mathrm{NH}_{4}^{+}$is an activator of PFK the decrease in its concentration will lead to a decrease in the carbon flux through the glycolytic pathway (Fig. 6).

2. A reduced flux of carbon through the glycolytic pathway (and therefore ultimately the citric acid cycle) will limit ATP generation, so the energy charge within 


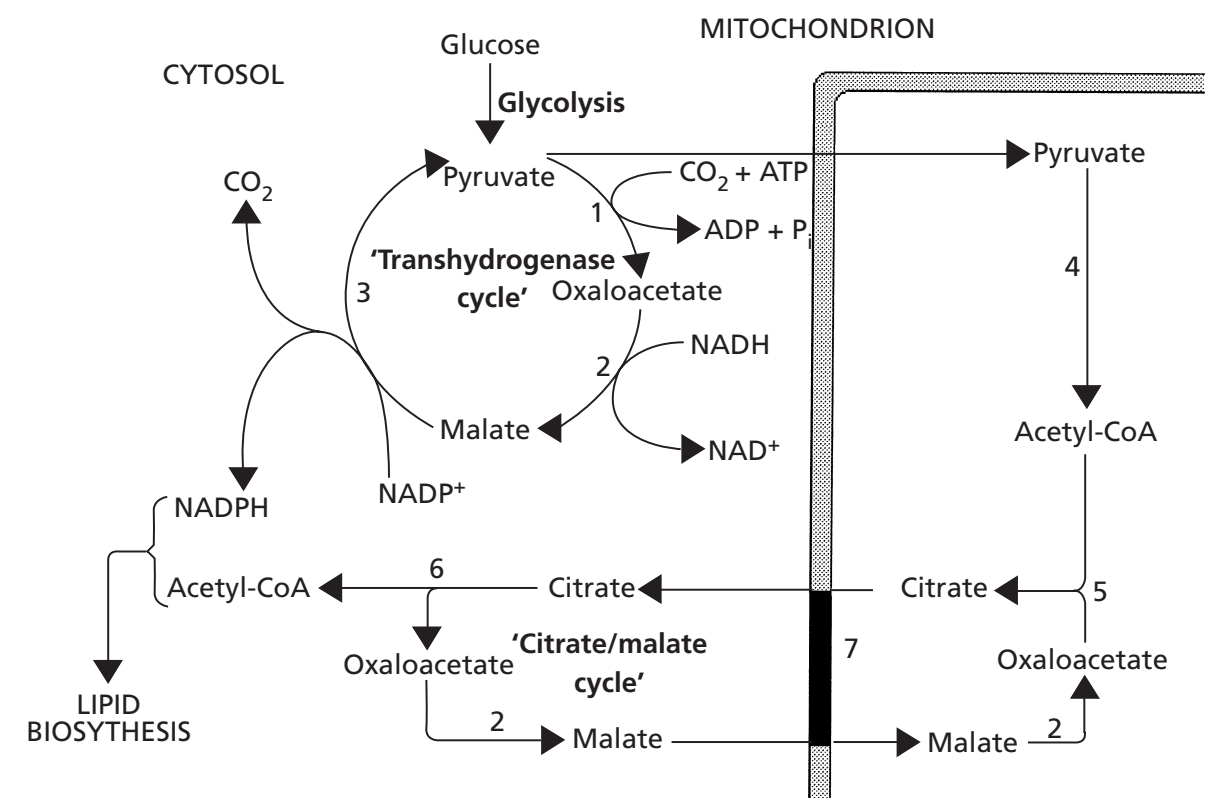

Fig. 6. Scheme showing how the proposed citrate/malate cycle and the cytosolic 'transhydrogenase' cycle could provide sufficient precursors (acetyl-CoA and NADPH) for lipogenesis in filamentous fungi. Enzymes: 1, pyruvate decarboxylase; 2, malate dehydrogenase; 3, malic enzyme; 4, pyruvate dehydrogenase; 5, citrate synthase; 6, ATP:citrate lyase; 7, citrate/ malate transport.

the cell will begin to decrease and this will activate AMP deaminase in order to maintain the energy charge within strictly controlled limits.

3. As a result of the activation of AMP deaminase, the AMP concentration will decrease and further limit the activity of the citric acid cycle (via NAD : ICDH activity), further restricting ATP generation; this will lead to a feed-forward process so that the energy charge can only be maintained by decreasing the total adenylate pool to a minimum level (approx. $50 \%$ of its trophophase level). Flux through the citric acid cycle will be further limited to a basal level, thereby restricting the supply of intermediates for anabolic processes, which will be further down-regulated by the decreased cellular ATP concentration, bringing them into line with the growthlimited environment.

4. When NAD: ICDH activity falls, citrate accumulates, which could further limit PFK activity. Citrate is translocated into the cytosol for cleavage by ATP: citrate lyase to provide cytosolic acetyl-CoA for lipogenesis.

5. The cytosolic pyruvate carboxylase together with ATP: citrate lyase and malate dehydrogenase allow a 'transhydrogenase cycle' to generate cytosolic NADPH independently from the 'citrate/malate cycle' (Evans et al., 1983), thereby providing sufficient reducing power for lipogenesis.

That Mc. circinelloides and Mort. alpina have such an involved mechanism for the sensing of oncoming Nlimited growth should not be a surprise. These fungi are commonly isolated from soil, which is a N-limited habitat, so that intricate mechanisms to deal with $\mathrm{N}$ - depletion from the environment would be an expected environmental adaptation.

\section{ACKNOWLEDGEMENTS}

The authors would like to express their gratitude to Mrs Maureen Ewing, Mrs Janet Stephenson and Mr David Grantham for their expert technical assistance throughout this work. J. P. Wynn was supported by a Link award from the BBSRC in collaboration with Avecia, Roche and Newtec, A. A. Hamid by a scholarship from the Universtii Kebangsaan, Malaysia, and Y. Li by the University of Hull.

\section{REFERENCES}

Atkinson, D. A. (1977). Cellular Energy Metabolism and its Regulation. New York: Academic Press.

Atkinson, D. E., Hathaway, J. A. \& Smith, E. C. (1965). Kinetics of regulatory enzymes: kinetic order of the yeast diphosphopyridine nucleotide isocitrate dehydrogenase reaction and a model for the reaction. J Biol Chem 240, 2682-2690.

Bartels, P. D. \& Jensen, P. J. (1979). Role of AMP in regulation of the citric acid cycle in mitochondria from bakers yeast. Biochim Biophys Acta 582, 246-259.

Botham, P. A. \& Ratledge, C. (1979). A biochemical explanation for lipid accumulation in Candida 107 and other oleaginous micro-organisms. J Gen Microbiol 114, 361-375.

Böttger, I., Wieland, O., Brdiczka, D. \& Pette, D. (1969). Intracellular localisation of pyruvate carboxylase and phosphoenolpyruvate carboxylase in rat liver. Eur J Biochem 8, 113-119.

Boulton, C. A. \& Ratledge, C. (1983). Use of transition studies in continuous cultures of Lipomyces starkeyi, an oleaginous yeast, to investigate the physiology of lipid accumulation. J Gen Microbiol 129, 2871-2876. 
Bradford, M. M. (1976). A rapid and sensitive method for the quantitation of microgram quantities of protein utilizing the principle of protein-dye binding. Anal Biochem 72, 248-254.

Chaney, A. L. \& Marbach, E. P. (1962). Modified reagents for determination of urea and ammonium. Clin Chem 8, 130-132.

Dagley, S. (1974). Citrate UV spectrophotometric determination. Methods Enzymatic Anal 3, 1562-1565.

Evans, C. T. \& Ratledge, C. (1983). Biochemical activities during lipid accumulation in Candida curvata. Lipids 18, 630-635.

Evans, C. T. \& Ratledge, C. (1985a). The role of $\mathrm{NAD}^{+}$: isocitrate dehydrogenase in lipid accumulation by the oleaginous yeast Rhodosporidium toruloides CBS 14. Can J Microbiol 31, 845-850.

Evans, C. T. \& Ratledge, C. (1985b). Possible regulatory roles of ATP: citrate lyase, malic enzyme, and AMP deaminase in lipid accumulation by Rhodosporidium toruloides CBS 14. Can J Microbiol 31, 1000-1005.

Evans, C. T., Scragg, A. H. \& Ratledge, C. (1983). A comparative study of citrate efflux from mitochondria of oleaginous and nonoleaginous yeasts. Eur J Biochem 130, 195-204.

Kendrick, A. \& Ratledge, C. (1992). Desaturation of polyunsaturated fatty acids in Mucor circinelloides and the involvement of a novel membrane-bound malic enzyme. Eur J Microbiol 209, 667-673.

Klitsch, W. M., Kubicek, C. P. \& Scrutton, M. C. (1991). Intracellular location of enzymes involved in citrate production by Aspergillus niger. Can J Microbiol 37, 823-827.

Knowles, C. J. (1977). Microbial metabolic regulation by adenine pools. Symp Soc Gen Microbiol 27, 241-283.

Kornberg, A. (1955). Isocitric dehydrogenase of yeast (TPN). Methods Enzymol 1, 705-709.

Kyle, D. J. (1997). Production and use of a single cell oil highly enriched in arachidonic acid. Lipid Technol 9, 116-121.

Mitsushima, K., Shinmyo, A. \& Enatsu, T. (1978). Control of citrate and 2-oxoglutarate formation in Candida lipolytica mitochondria by adenine nucleotides. Biochim Biophys Acta 538, 481-492.

Osmani, S. A. \& Scrutton, M. C. (1985). The subcellular localisation and regulatory properties of pyruvate carboxylase from Rhizopus arrhizus. Eur J Biochem 147, 119-128.

Parvin, R. (1969). Citrate synthase from yeast. Methods Enzymol 13, 16-19.

Rangasamy, D. \& Ratledge, C. (2000). Genetic enhancement of fatty acid synthesis by targeting rat liver ATP: citrate lyase into plastids of tobacco. Plant Physiol 122, 1231-1238.

Ratledge, C. (1997). Microbial lipids. In Biotechnology, 2nd edn, vol. 7, pp. 133-197. Edited by H. J. Rehm \& G. Reed. Weinheim: $\mathrm{VCH}$.

Ratledge, C. (2000). Look before you clone - A comment on 'Properties of Aspergillus niger citrate synthase and effects of citA overexpression on citric acid production' by G. H. G. Ruijter, H. Panneman, D.-B. Xu \& J. Visser FEMS Microbiol Lett 184 (2000), 35-40. FEMS Microbiol Lett 189, 317-318.

Roehr, M., Kubicek, C. P. \& Komínek, J. (1996). Citric acid. In Biotechnology, vol. 6, Products of Primary Metabolism, 2nd edn, pp. 311-145. Edited by H. J. Rehm, G. Reed, A. Pühler \& P. Stadler. Weinheim: VCH.

Rohde, M., Lim, F. \& Wallace, J. C. (1991). Electron microscopic localisation of pyruvate carboxylase in rat liver and Saccharo- myces cerevisiae by immunogold procedures. Arch Biochem Biophys 290, 197-201.

Ruijter, G. H. G., Panneman, H., Xu, D.-B. \& Visser, J. (2000). Properties of Aspergillus niger citrate synthase and effects of citA overexpression on citric acid production. FEMS Microbiol Lett 184, 35-40.

Schwitzguebel, J. P., Moller, I. M. \& Palmer, J. M. (1981). Changes in density of mitochondria and glyoxysomes from Neurospora crassa: a re-evaluation utilizing silica sol gradient centrifugation. J Gen Microbiol 126, 289-295.

Seubert, W. \& Weicker, H. (1969). Pyruvate carboxylase from Pseudomonas. Methods Enzymol 13, 258-260.

Siebert, G. (1974). Isocitrate UV spectrophotometric determination. Methods Enzymatic Anal 3, 1570-1576.

Solodovnikova, N. Y., Sharyshev, A. A., Medentsev, A. G., Voloshin, A. N., Morgunov, I. G. \& Finogenova, T. V. (1998). Dynamics of the adenine nucleotide pool in Yarrowia lipolytica cells overproducing organic acids. Microbiology 67, 28-32.

Sols, A. \& Salas, M. (1966). Phosphofructokinase III. Yeast. Methods Enzymol 9, 436-442.

Sottocasa, G. L., Kuylenstierna, B., Ernster, L. \& Bergstrand, A. (1967). Separation and some enzymatic properties of the inner and outer membranes of rat liver mitochondria. Methods Enzymol 10, 448-463.

Speilmann, H., Jacob-Müller, U. \& Schulz, P. (1982). Simple assay of $0 \cdot 1-1.0 \mathrm{pmol}$ of ATP, ADP and AMP in single somatic cells using purified luciferin luciferase. Anal Biochem 113, 172-178.

Taylor, D. J., Crabtree, B. \& Smith, G. H. (1978). The intracellular location of pyruvate carboxylase, citrate synthase and 3hydroxyacyl-CoA dehydrogenase in lactating rat mammary gland. Biochem J 171, 273-275.

Van Urk, H., Schipper, D., Breedveld, G. J., Mak, P. R., Scheffers, W. A. \& van Dijken, J. P. (1989). Localisation and kinetics of pyruvate-metabolizing enzymes in relation to aerobic alcoholic fermentation in Saccharomyces cerevisiae CBS 8066 and Candida utilis CBS 621. Biochim Biophys Acta 992, 78-86.

Vanheeswijck, R. (1984). The formation of protoplasts from Mucor species. Carlsberg Res Commun 49, 597-609.

Woo, N. Y. S. \& Chiu, S. F. (1997). Metabolic and osmoregulatory responses of the sea bass Lates calcarifer to nitrate exposure. Environ Toxicol Water Quality 12, 257-264.

Worthington Enzymes (1979). Pyruvate kinase. In Enzymes and Related Biochemicals, pp 179-180. Bedford, MA: Millipore Corporation.

Wynn, J. P. (1998). Microorganisms as sources of nutritionally important polyunsaturated fatty acids. Proceedings of the 12th Forum on Applied Biotechnology, part 1, pp. 1215-1222. ISSN 0368-9697.

Wynn, J. P., Kendrick, A. \& Ratledge, C. (1997). Sesamol as an inhibitor of growth and lipid metabolism in Mucor circinelloides via its action on malic enzyme. Lipids 32, 605-610.

Wynn, J. P., Hamid, A. A., Midgley, M. \& Ratledge, C. (1998). Widespread occurrence of ATP:citrate lyase and carnitine acetyltransferase in filamentous fungi. World $J$ Microbiol Biotechnol 14, 145-147.

Wynn, J. P., Hamid, A. A. \& Ratledge, C. (1999). The role of malic enzyme in the regulation of lipid accumulation in filamentous fungi. Microbiology 145, 1911-1917.

Received 16 March 2001; revised 25 June 2001; accepted 4 July 2001. 